\title{
Feeding ecology and territoriality of the Cactus Finch Geospiza scandens on Isla Daphne Major, Galápagos
}

\author{
S.J. Millington and P.R. Grant \\ Division of Biological Sciences, University of Michigan, Ann Arbor, MI 48109, USA
}

\begin{abstract}
Summary. In this study we investigated the relationship between food availability, feeding ecology and territoriality in a population of Cactus Finches, Geospiza scandens, on Isla Daphne Major, Galápagos, between 1979 and 1981.

We monitored the phenologies of the principal food types on the island and related them to changes in the feeding ecology of $G$. scandens. Feeding patterns closely tracked the availability of resources, with a similar pattern in each of the three years. Birds relied heavily on Opuntia fruits in the dry season.

G. scandens defends year-round territories based on Opuntia. Variation in Opuntia phenologies between individual territories and between years was documented in order to provide a measure of territory quality over the three years. A correlation was demonstrated between the area of cactus within a territory and mating success of the owner. We suggest that territory quality also affects the survival of the owners during periods of food scarcity and that the mating and survival advantage of a high-quality territory occur at different times and to different degrees in different years. Hence the importance of territorial quality can only be judged over a long-term period in these long lived and sedentary birds.
\end{abstract}

\section{Introduction}

Janzen (1980) commented, "There is no general, allpurpose method of description of resources for small, tropical terrestrial birds. To understand food resources for the birds in a habitat or for a particular species of bird, one has to determine what the bird(s) feed on and hand-tailor a census technique that collects data in a manner that correlates well with the actual resources taken by the bird." This has proved difficult because most birds feed on a wide variety of seasonally available foods (e.g. Karr 1976). However, Darwin's finches on Isla Daphne Major in the Galápagos provide an ideal subject for a detailed study of the interaction between birds and their food supply, because 1) the environment is simple, 2) the seasonally varying food supply can be relatively easily documented, and 3 ) the feeding behavior of the birds is readily observed.

Previous studies of the feeding characteristics of finches on Galapagos have been made during relatively short periods of time (Abbott et al. 1977; Smith et al. 1978; Grant

Offprint requests to: P.R. Grant and Grant 1980; Schluter 1982). Boag (1981) studied the Daphne Major finch community from 1976 to 1978 but did not quantify variations in food supply within most seasons. The purpose of the present study is to establish links between food supply, feeding behavior and territoriality in the Cactus Finch Geospiza scandens on Isla Daphne Major. The study was conducted for three years, 1979 to 1981, because, as is becoming increasingly appreciated, long-term studies (> one year) are necessary to understand the selective forces affecting territoriality (e.g. see MacLean and Seastedt 1979).

\section{Methods}

The physical characteristics of Daphne Major have been described elsewhere (Grant et al. 1975; Grant and Grant 1980 ; Boag 1981). S.J.M. and his colleagues visited this island from early January until late June in each year from 1979 to 1981 . Additional visits were made in late September 1979 (two weeks) and late July 1980 (one week). Plant phenology and feeding ecology were recorded at each visit and estimates of territory size were made in 1979 and 1980.

\section{Plant phenology}

Guided by the observations of Boag (1981), we selected the four most important categories of food plants for detailed study.

a) Opuntia echios. Weekly counts of flowers and fruits were made on the same ten plants on one area of the island (the plateau; see map in Grant et al. 1975). To determine the length of time fruits remain on the plant we checked one pad on each of four bushes every two days from midJanuary to early May 1980, and recorded the state of the flowers and fruits at those times. Twenty-four fruits were thus followed from flowering onwards. For each flower we noted whether or not the stigma had been snipped or otherwise damaged by a cactus finch, as described by Grant and Grant (1981).

b) Bursera malacophylla. Ten selected trees on the plateau were monitored approximately every week. On each occasion we recorded the state of leaves and flowers and the number of fruits. To quantify the availability of caterpillars on the trees we collected (with a pair of tweezers) as many caterpillars as possible (0-64) in a period of twenty minutes. 
Table 1. Relationship between number of Opuntia flowers and percent with stigmas snipped, 1980-1981

\begin{tabular}{|c|c|c|c|c|c|c|c|c|c|c|c|c|c|c|}
\hline & \multicolumn{14}{|l|}{1981} \\
\hline & \multicolumn{3}{|l|}{ Jan } & \multicolumn{2}{|c|}{ Feb } & \multicolumn{3}{|c|}{ March } & \multicolumn{2}{|c|}{ Apr } & \multicolumn{2}{|c|}{ May } & \multicolumn{2}{|r|}{ Jun } \\
\hline Buds & 827 & 622 & 393 & 112 & 40 & 17 & 24 & 39 & 37 & 8 & 3 & 2 & 0 & 0 \\
\hline Total \# flowers & 167 & 106 & 77 & 24 & 9 & 5 & 1 & 0 & 8 & 5 & 1 & 0 & 0 & 0 \\
\hline \multirow[t]{2}{*}{$\%$ Flowers snipped } & 41 & 54 & 51 & 54 & 67 & 20 & 100 & - & 0 & 0 & 100 & - & - & - \\
\hline & Jan & & & & $\mathrm{Feb}$ & & & & & arch & & & & Apr \\
\hline Date & 1 & 16 & 25 & & 4 & 14 & & 28 & & & 16 & 21 & & 16 \\
\hline Buds & 534 & 291 & 259 & & 140 & 110 & & 70 & & & 40 & 28 & & 0 \\
\hline Total \# flowers & 103 & 94 & 66 & & 30 & 35 & & 16 & & & 5 & 7 & & 1 \\
\hline
\end{tabular}

c) Portulaca howelli. Variations in the number of flowers were quantified by counting the blooms twice-weekly on 20 plants in 1979 and daily on 50 different plants on the outer slope in 1980-1981. Flower buds are often infested by small moth caterpillars ("budworms") which destroy the buds and prevent flowering. The abundance of budworms was quantified using the same method as for Bursera caterpillars (collecting as many as possible in $20 \mathrm{~min}$ ), approximately every two days during the wet season, JanuaryMay.

d) Herbs. This group of plants, mostly annuals, shows a marked response to rain. Counts of flowers and fruits were made approximately weekly on each of five to ten plants of selected species (e.g. Tribulus cistoides, Heliotropium angiospermum, Boerhaavia erecta). The time of appearance of other annual species (e.g. Amaranthus sclerantoides, Cenchrus platyacanthus) was noted.

\section{Feeding ecology}

To quantify the feeding characteristics of the birds, two observers, $50 \mathrm{~m}$ apart, followed a set route of approximately $1 \mathrm{~km}$ and recorded each bird observed feeding and the item it consumed. The birds are very tame, and most items were readily identified as they were eaten. Sometimes it was difficult to distinguish between different kinds of small seeds on the ground, and these were categorized as one item. The route was designed to cover a representative portion of the island in terms of available food types. In mid-1979, 85\% of the birds had been individually colorbanded, and by the end of the study the proportion had risen to $96 \%$. This figure was obtained from estimating the percentage of unbanded birds during regular censuses. Thus it was possible to minimize recording the same bird twice. An attempt was made to obtain 25 observations each time. These "feeding walks" were carried out approximately every one to two weeks. The tameness of the birds and the openness of the terrain meant that specific feeding activities were unlikely to have been underrecorded to a significant extent.

\section{Territories}

Territories were mapped, with boundaries delineated by song, displays and chases. The area of each territory was not measured, but to obtain a comparative measure of territory quality we calculated the area of cactus in each of 20 territories by measuring axes of the larger clumps with a tape measure, and then by estimating the area of each smaller clump as a proportion of the larger ones. Six territories were chosen for intensive monitoring and all cactus buds, flowers and fruits (fertile and infertile) were counted in May and September 1979 and January and April, 1980. Flowers were also counted in the 1981 wet season. The proportion of flowers with the stigmas snipped was recorded on each count (Table 1). Finches often snip or otherwise damage the stigmas of Opuntia flowers or buds upon which they feed, probably to facilitate pollen and nectar removal (Grant and Grant 1981). The number of flowers and the proportion "snipped" were recorded for a number of other territories.

\section{Rainfall}

Rainfall was recorded using a plastic wedge rain gauge.

\section{Results}

\section{Rainfall}

The pattern of rainfall is shown in Fig. 1. Similar patterns occurred in 1979 and 1980, with bouts of rain in early February and mid-April, but in 1981 there was a single, high peak in late March. The annual totals for 1979-1981 were $68.6,53.5$ and $79.5 \mathrm{~mm}$ respectively.

\section{Plant phenology}

a) Opuntia echios. Figure 2 summarises cactus phenology. Buds first appear in September, and the peak flowering period probably occurs from December to January. A rapid decline occurs through February and few flowers are left by March. Later rainfall does not appear to stimulate further flowering (e.g. the April rain in 1979 and 1980). Individual flowers last only 2-3 days. Fruit numbers peak in February to March, coincident with the flowering decline. Thereafter numbers fall, as fruits drop off the pads, until after the next flowering in September. Relatively few old 


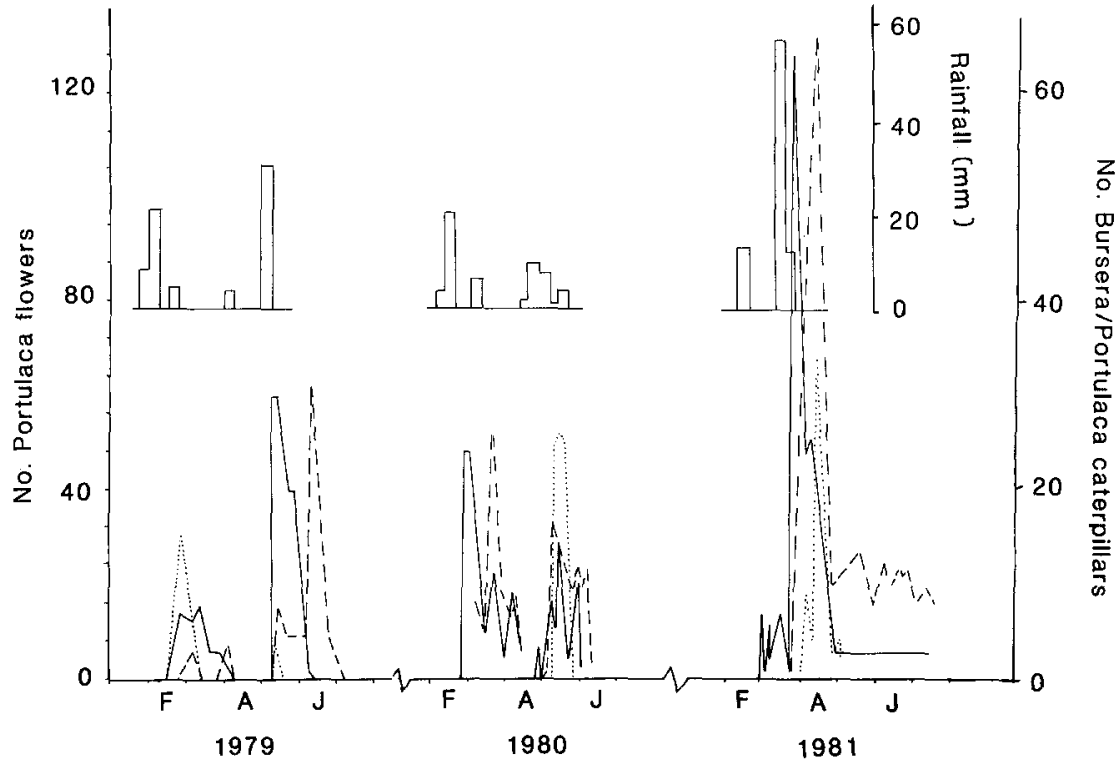

Fig. 1. Caterpillar response and Portulaca flower response to rainfall, 1979-1981 ㄷ. rainfall; -... Portulaca flowers; - Portulaca budworms; ..... Bursera caterpillars

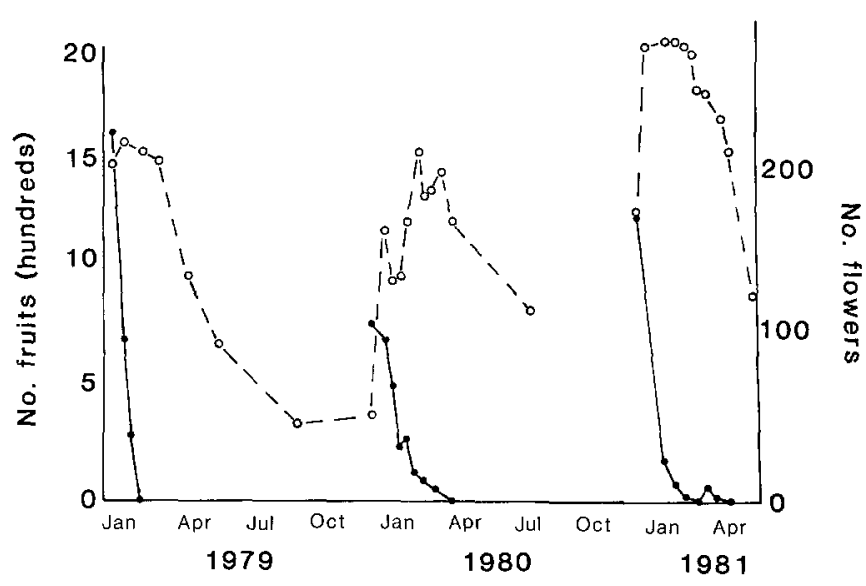

Fig. 2. Numbers of flowers and fruits on ten Opuntia bushes, 1979-1981 - - flowers; -- - fruits

fruits are present on the bushes at this time. It seems likely that the timing of flowering is an evolutionary adjustment to climate that results in most fruits being formed in the wet season. This is the only time that the necessary moisture is available to develop the fleshy pulp around the seeds (see Wiggins and Porter 1971).

Of the 24 fruits followed from flowering onwards, 16 fell before early May. The stigmas of all 16 had been snipped previously. These fruits stayed on the pads between 2 and 57 days $(\bar{x} 24.1 \pm S D 20.0)$. They were shrivelled and presumably not fertilised. Those that were opened contained no seeds $(N=6)$. The other eight fruits remained on the bush at least until early May and had thus been present for between 82 and 110 days. Six of these previously had undamaged stigmas. The fruits were fully developed and presumably contained seeds. It is possible that the two "snipped" fruits had been fertilised before snipping. Thus it appears that 1) stigma snipping results in no, or reduced, fertilisation as shown by Grant and Grant (1981) and 2) infertile fruits fall much earlier than fertilised ones. Grant and Grant (1981) showed that on Isla Santa Cruz some fruits remained on pads for up to 475 days. Few of the fruits on Daphne appear to remain on bushes for this length of time (see p. 11 and Fig. 5).

The proportion of flowers on the ten sample bushes that had their stigmas snipped varied. However, the proportion of fruits on bushes that were judged fertile remained fairly constant between March 1979 and June 1981 at between $61 \%$ and $88 \%$.

b) Bursera malacophylla. This tree species is patchily distributed over the island, being concentrated mainly on the plateau and southern inner slope of the main crater. The trees are leafless in the dry season, but respond rapidly to rain, coming into leaf within five days, producing flowers within the next five to ten days and 1 to 2 months later producing mature fruits. These fruits are highly edible to finches, but during the study period relatively few were produced and birds did not feed on them to a significant extent.

Bursera trees are host to caterpillars which feed on the leaves. This is an important food source for the finches. Caterpillars were observed almost as soon as the trees came into leaf (Fig. 1).

c) Portulaca howelli. This is a low, fleshy perennial (Wiggins and Porter 1971) that forms most of the ground cover over much of the island. Like Bursera it remains leafless during the dry season, but rapidly comes into leaf during the onset of rain. Budworm numbers rise rapidly to a peak and then decline rapidly (Fig. 1). Coincident with this decline is an equally rapid rise in the number of flowers from the laterformed buds. In the absence of further rain all larvae and nearly all flowers have disappeared by two months after initial rainfall. In four out of five bouts of rainfall the peak flowering occurred approximately five weeks after the rainfall. It does not take this long for the flowers to develop because the buds are formed in only a few days, and a few of these develop into flowers within a week. There is a graded response by both plants and larvae to rainfall, varying apparently in parallel (Fig. 1). This explains the association between budworm numbers and flower numbers. In May 1980, the low larval infestation meant 
Table 2. Pattern of Portulaca flowering inside and outside two $2 \mathrm{~m} \times 1 \mathrm{~m}$ finch-proof exclosures, 1982

\begin{tabular}{|c|c|c|c|c|c|c|}
\hline & 17 Mar & $21 \mathrm{Mar}$ & $26 \mathrm{Mar}$ & 31 Mar & $5 \mathrm{Apr}$ & $11 \mathrm{Apr}$ \\
\hline No. flowers in exclosures & 5 & 10 & 13 & 20 & 2 & 20 \\
\hline No. flowers in the same area outside exclosures & 1 & 11 & 4 & 15 & 2 & 23 \\
\hline
\end{tabular}

that many of the early-flowering buds escaped predation, resulting in the earlier flowering peak, coincident with the budworm peak (Fig. 1).

To determine if the decline in budworm numbers is brought about by the foraging pressure of finches, flowering periods were compared between plants inside and outside two $2 \mathrm{~m} \times 1 \mathrm{~m}$ finch-proof exclosures in 1982. The patterns were very similar (Table 2), suggesting a negligible role for finch predation (data kindly supplied by L. Gibbs).

d) Herbs. Several annual species are important to finches as food sources as indexed by the relative amount of time spent feeding on them. The principal ones, in decreasing order of importance are, Boerhaavia erecta, Amarananthus sclerantoides, Cenchrus platyacanthus, Acalypha parvula, and Sida salviifolia. Buds, pollen, fruits, and various invertebrates are all occasionally taken from the living plants, and seeds of several species are important in the dry season when all plants are dead. There is a characteristic sequence of appearance of some of these plants. For example in 1981, Amaranthus appeared within 3 to 4 days of the rain, Boerhaavia in about two weeks and Cenchrus in about a month. Plant production, and production of seeds, varied among years in relation to rainfall.

\section{Feeding ecology}

With the onset of Opuntia flowering in September, adult finches feed almost exclusively on this plant, predominantly on the flowers from which they gain nectar and pollen (Grant and Grant 1981), but also on the fallen fruits. They continue to feed on Opuntia flowers (if present) and, to a lesser extent the fruits, during periods of rainfall from January onwards. However, rain results in the production of a wide array of food items not present in the dry season. Amaranthus shoots appear first and are readily eaten by the finches which then increasingly exploit the rising caterpillar populations on Bursera and Portulaca. When these decline the birds switch to Boerhaavia buds and fruits, and Portulaca flowers, the latter now abundant with the decline of the budworms. Later the unripe seeds of Cenchrus, if present, are exploited and the small seeds of other annuals are taken off the plants and from the ground (e.g. Amaranthus, Acalypha, Sida). As the number and variety of potential food items declines at the end of the wet season, the finches become more dependent on Opuntia fruits. Juvenile finches up to several months old cannot crack Opuntia seeds however, and rely almost exclusively on small seeds or Opuntia flowers and/or Portulaca flowers, if present. Thus in September 1979 birds of the year were noted feeding almost entirely on the small seeds of annuals.

This pattern of resource switching appears to be a consistent pattern, since it was observed in all three years. Tracking of the available resources is indicated by the high correlation between first the proportion of feeding observations on budworms and the estimated number of budworms

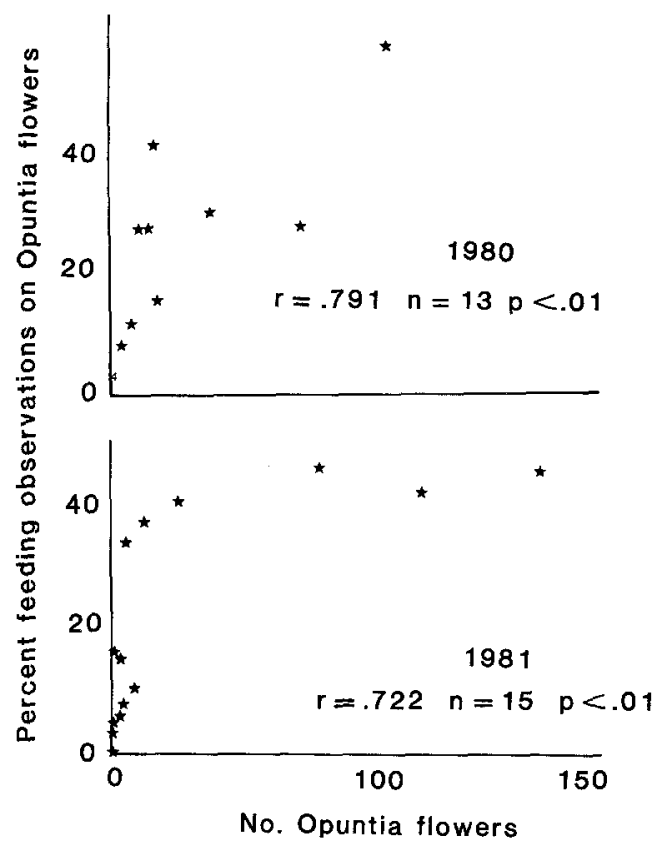

Fig. 3. Exploitation patterns of Opuntia flowers by G. scandens in 1980 and 1981

available (all years combined; $r=0.62, N=27, P=<0.01$ ), and second the proportion of feeding on Opuntia flowers and their abundance (1979 too few data; $1980 r=0.79, N=$ 13, $P=<0.01 ; 1981 r=0.72, N=15, P<0.01)$.

Different patterns of Opuntia exploitation were observed in the two years as shown in Fig. 3. This figure should be interpreted from right to left to indicate the decline in abundance of Opuntia flowers as the season progresses. Thus in 1980 there was a regular decline in flower feeding with a decrease in flower abundance (Fig. 3). In 1981 there was a typical Type II feeding response (Holling 1966). In the latter year birds fed disproportionately on flowers at high densities (with an apparent asymptote at about $50 \%$ of feeding observations) and then suddenly switched at low flower densities to other food types. The difference in exploitation between years results from a difference in the timing of rainfall. In 1981 birds fed on Opuntia flowers, even when flowers were scarce, until the rain fell in late March when they all switched to caterpillars and annuals. In 1980 the rain fell while Opuntia flowers were still relatively abundant and so birds fed both on these flowers and other items available as a result of the rain, and consequently the switch was not so abrupt.

In contrast to these results, the proportion of feeding on Opuntia fruits was negatively correlated with the abundance of budworms (all years combined $r=-0.41, N=28$, $P<0.05)$ and of Opuntia flowers (1980-1981 $r=-0.50, N=$ $22, P<0.05)$. The fact that these are significant despite the potentially confounding effects of the difference in timing of the rains and of the Opuntia flowering season indicates 


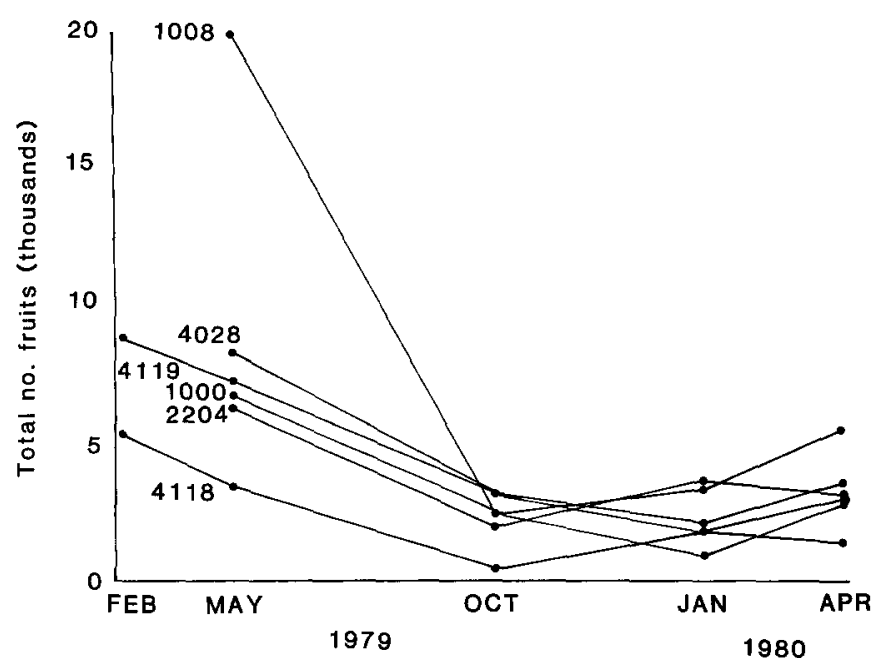

Fig. 4. Total numbers of Opuntia fruits on the bush in six territories, 1979-1980

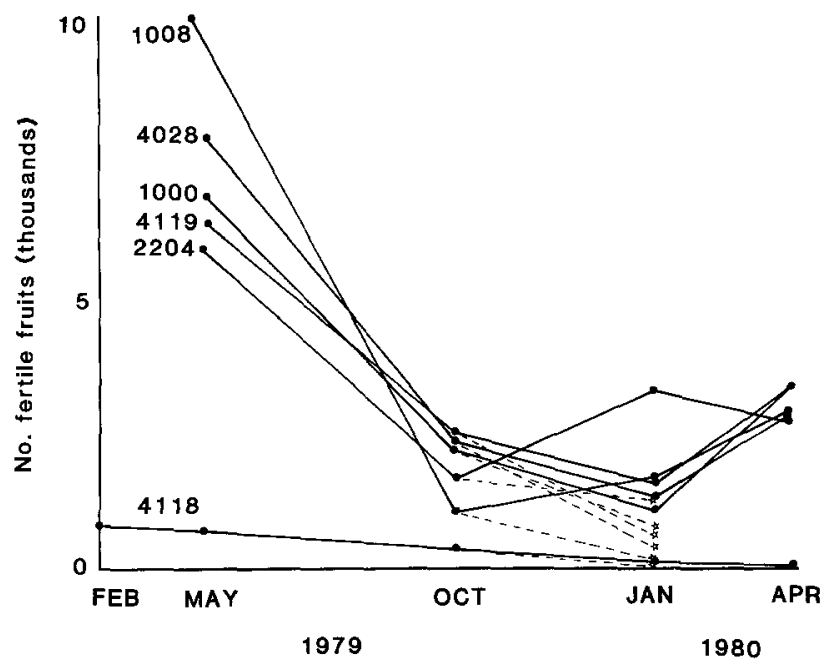

Fig. 5. Number of fertile fruits on the bush in six territories, 1979-1980

that the proportion of feeding on Opuntia fruits decreases with increasing availability of alternative food types. Thus cactus finches rely almost exclusively on Opuntia fruits only when other food types are unavailable.

\section{Variation in Opuntia phenology}

a) Between territories. Opuntia fruit numbers peaked at the end of the flowering season and then declined through the dry season in the six monitored territories (Fig. 4) and on the ten sample bushes. In both sets of data the lowest number was reached sometime during the next flowering season, before the majority of flowers had formed new fruits (Fig. 5). In 1980 the low point was reached before January in three territories and between January and April in the other three. The former were on the northern outer slope and the latter were on the eastern slope and crater and form part of a clear geographical division between "early' and 'late' flowering territories (see Fig. 6 and legend). The division accounts for the observation that in late September

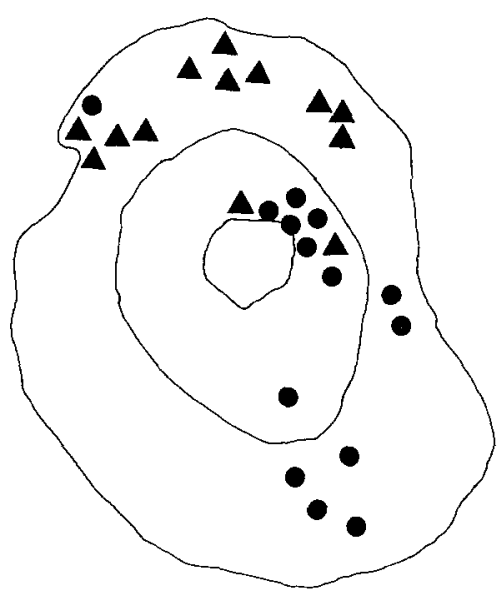

Fig. 6. Distribution of early-flowering and late-flowering territories on Daphne in 1980. Territories marked as early or late if $>10 \%$ decrease or increase in total flower number between 21 January and 2 February $1980 . \bullet=$ early; $₫=$ late

1979, at the very beginning of the flowering season, the only bushes in flower were situated on the southern inner slope and plateau. Furthermore, the ten sample bushes on the plateau had apparently produced maximum flower numbers before S.J.M.'s arrival in early January 1980.

A large number of fruits were of no value to $G$. scandens because they were infertile and hence contained no, or few, seeds. Cactus finches feed to a large extent on Opuntia seeds but only occasionally on the aril and then probably to obtain moisture. Figure 5 shows the number of fertile fruits per territory for the six territories. The pattern is generally consistent among territories except that in territory 4118 fertile fruit numbers started at a low number and continued to decrease throughout the study period. Figure 5 also shows the production of new fruits between September and January. The old fruits at this time are distinguishable from the new fruits by being much larger and yellower. The "earlier-flowering" territories (1000, 4028 and 4199) show a greater fruit production by January than the late-flowering ones.

Comparison of Figs. 4 and 5 indicates considerable variation among territories in the proportion of fruits that are fertile. There are at least two reasons for this. Some of the cactus clumps are rather large as a result of bushes or individual pads falling and propagating vegetatively. Often these clumps are at the bottom of slopes and may consist of very few individual plants. Opuntia on Daphne has been shown to be an obligate outcrosser (Grant and Grant 1981). Many of these flowers may not receive pollen from a genetically different plant, and so produce infertile fruits. This is especially likely to be true if a bird's territory consists of one or two of these clumps. It was noticed that many of the large clumps contained a high proportion of infertile fruits (e.g. territory 1008).

A second reason is the practice of stigma snipping. In late September 1979 all but one of 25 Opuntia flowers in several territories had their stigmas snipped. However, in another territory 14 out of a further 15 flowers had stigmas intact, indicating substantial individual variation among birds in this behavior, assuming that the territory owners are responsible for the amount of snipping within their terri- 
tory. Table 3 provides further evidence that there is considerable variation among territories in the amount of stigmasnipping. The consequence of the effects of reduced outcrossing and stigma-snipping can be examined by a comparison of two territories. The proportion of stigma-snipping in territory 1008 was extremely low, yet it contained a high proportion of infertile fruits. The territory had two large clumps at the bottom of the crater and there was probably little outcrossing by the cactus. Moreover, large clumps on the crater floor typically contain a high percentage of infertile fruits (pers obs). The area of cactus contained in craterfloor territories is much greater than the mean area of territories on the inner and outer slopes $\left(206.5 \pm 23.7 \mathrm{~m}^{2} S E\right.$ versus $\left.113.0 \pm 8.6 \mathrm{~m}^{2} S E, t_{24}=3.48, P<0.01\right)$. This suggests that birds in these territories need to compensate for high cactus fruit infertility by defending larger territories. Territory $4118 \mathrm{had}$ a consistently high incidence of stigma-snipping. This territory had by far the lowest proportion of fertile fruits, yet the temporal pattern of total fruit production between September 1979 and January 1980 was similar to the other territories (Fig. 4). Furthermore it did not contain a single large cactus clump but rather dispersed bushes. Thus stigma-snipping is likely to be responsible for the high level of infertile fruits since fruit inviability is unlikely in this territory.

\section{b) Between years}

There was considerable variation between years in both the amount and pattern of flower production. For seven monitored territories the average maximum flower number in 1980 was twice that of $1981(169.9 \pm 19.5$ SE versus $82.7 \pm 7.7 S E$; Wilcoxon matched pairs sign rank test $P<$ 0.05 ). The 1980 figure is likely to be conservative since only occasional counts were made in that year whereas flowers were counted regularly in 1981.

There was also variation in the length of the flowering period. In 1979 there were virtually no flowers after midFebruary; in 1980 flowers were present through to April and in 1981 flowering was almost at an end in mid-March. To give a quantitative example, there were significantly more flowers in the six territories on 4 April, 1980 than on 7 April, 1981, when flower numbers were declining $(32.6 \pm 7.3$ SE versus $21.5 \pm 7.6 \mathrm{SE}$; Wilcoxon matched pairs sign rank test $P<0.05$ ) despite the fact that the cactus showed a response to heavy rainfall in late March 1981.

Both the amount and pattern of stigma snipping differed between years. Table 3 shows a higher proportion of stigmas snipped in 1981 than in 1980. The difference is significant between mid-January each year (Wilcoxon matched pairs sign rank test $N=5, P<0.05$ ) and between mid-January 1980 and late January 1981, the peak of flowering in that year (Wilcoxon matched pairs sign rank test $N=6, P<0.05$ ). Moreover there were different patterns of stigma-snipping in 1980 and 1981 in relation to flower abundance. In 1980 there was a highly significant negative correlation between the proportion of stigmas snipped and the number of flowers present $(r=-0.75, N=20, P<0.01)$ although the relationship resembles a Type II pattern of curvilinearity (Holling 1966). In 1981 there was no correlation $(r=-0.01, N=6, P>0.01)$. The difference can be explained in terms of a difference in the pattern of exploitation of Opuntia flowers (see Fig. 3). In 1980 the number of flowers exploited declined with a decrease in absolute flower
Table 3. Percentage flowers with damaged stigmas, with total number of flowers shown in parentheses

\begin{tabular}{llll}
\hline Territory & 17 Jan 80 & 17 Jan 81 & 26 Jan 81 \\
\hline 4,119 & $25(120)$ & $46(68)$ & $62(77)$ \\
1,000 & $18(123)$ & $41(44)$ & $27(79)$ \\
4,028 & $7(152)$ & $28(58)$ & $40(78)$ \\
4,113 & $92(123)$ & $92(88)$ & $94(99)$ \\
2,204 & $22(165)$ & $26(34)$ & $44(63)$ \\
1,008 & $2(272)$ & n.c. & $41(120)$ \\
& $X_{5}^{2}=425.96$ & $X_{4}^{2}=82.61$ & $X_{5}^{2}=43.56$ \\
& $p<0.001$ & $p<0.001$ & $p<0.001$ \\
\hline
\end{tabular}

$X^{2}$ values are comparisons of the number of snipped and unsnipped flowers among specified territories on each date n.c. $=$ not counted

abundance. As flowers became scarcer, more were attacked at the bud stage. Stigmas are more likely to be damaged if the bud is attacked rather than the flower (Grant and Grant 1981). In 1981, by contrast, there was a sharp decrease in flower exploitation late in the season as birds switched to other foods (Fig. 3) and so late buds were probably not opened.

Total fruit numbers and fertile fruit numbers each showed a $61 \%$ decline from early May 1979 to early April 1980. Presumably 1979 was a year of high fruit production (and flower production), perhaps as a consequence of the high 1978 rainfall. 1980 and 1981 were poor years in terms of flower and fruit production possibly because of the low rainfall in the preceding years. There is further indirect evidence for an effect of the previous year's rainfall on the magnitude of the flowering response. In January 1982 the Opuntia flowering was the highest since early 1979 (T.D. Price pers comm), and rainfall in the preceding wet season (1981) was the highest since 1978.

\section{c) Effects of territory size}

Territories are based on cactus. Territorial boundaries are defined by cactus bushes and areas of open ground. Portulaca and Bursera are not defended unless they are between cactus bushes. Territories vary greatly in size but vary much less in area of cactus (Boag 1981 and pers obs). The mean area of cactus in 26 territories of adult male $G$. scandens on the island was $141.8 \pm 12.6 \mathrm{~m}^{2} S E$ (ranging from $49 \mathrm{~m}^{2}$ to $292 \mathrm{~m}^{2}$ ). All adult birds maintained the same territories from year to year with minor adjustments following the disappearance of neighbors. Only 10 out of 102 males $(9.8 \%)$ holding territory disappeared between 1979 and 1981.

Territories occupied by males in immature plumage were much smaller $(54.0 \pm 7.9 S E)$ than those occupied by the generally older adult-plumaged (black) males referred to above $\left(t_{27}=5.47, P<0.001\right)$.

A sex ratio bias in favor of males occurred after the 1977 drought. This resulted in many males being unmated in early 1979 (Millington MS). Those males that remained mated through 1979 (some females changed mates) had significantly larger territories than those who did not, including the unmated birds $\left(t_{18}=4.03 \quad P<0.001\right)$. Furthermore, those males that obtained one-year old females as mates in 1979 had larger territories than those remaining unmated 
(Mann-Whitney $U_{2,5}=0 \quad P=0.05$, one-tailed). These comparisons exclude the crater floor territories, which as previously noted, were larger but tended to contain a high proportion of infertile fruits because of reduced outcrossing. The differences provide evidence that territory quality may be important in the choice of mates by females (see Price MS). But within a breeding bout reproductive success has been shown to be very similar among breeding pairs, irrespective of territory size (Millington MS).

\section{Discussion}

The results show that the pattern of exploitation of most food types is very closely tied to the phenology of those food types, which in turn is governed by the timing and amount of rainfall. Thus within any one year the feeding behavior of the finches may be largely predicted from a knowledge of the available food supply. However, between years these phenologies are very different. For example, 1973, 1976 and 1978 were years of high Bursera fruit production and finches fed extensively on these berries in these years (Grant et al. 1976; Boag 1981). But during the study period, production was low and birds rarely fed on the fruits.

Close linking of exploitation patterns with a seasonally varying food supply has also been shown in hummingbirds and other species of birds dependent on nectar as a food source. In these species territoriality has been shown to be based on short-term (daily) food requirements (Stiles 1973; Gill and Wolf 1975). However, these are migrating or nomadic species that move elsewhere when the food supply declines or fails. Thus they differ from the nonmigratory Cactus Finch which is dependent on local food sources year-round.

In the wet season there is low variance in breeding performance in any one breeding bout and variations in territory quality appear to be relatively unimportant contributors to this variance (Millington MS). There is evidence, e.g. from Portulaca, that in the wet season food supplies may not be limiting. Instead, whether or not an individual has a mate is the critical factor in determining breeding success. Approximately half of the total variance in fledging success is due to variance in mating success (Price MS). The present study shows mating success to be strongly correlated with territory size (cf. Zimmerman 1971; O’Donald 1977).

Food supply may be limiting in the dry season (e.g. Smith et al. 1978). Cactus finches feed almost exclusively on Opuntia fruits in the dry season, before the flowering season begins in September to October, especially if there are few small seeds produced in the previous wet season. Thus another advantage to having a large territory is enhancement of the probability of survival through access to a sufficient food supply during periods of food scarcity.

This last point can be illustrated with an example. The mean number of fertile fruits for the six territories was approximately 1800 in September 1979. If we assume an annual $61 \%$ decline in fruit number, such as occurred between May 1979 and April 1980, 700 fruits would have been left in September 1980. Given the 50\% lower flower production in 1981 compared to 1980 and translating this into fruit production, about 350 fruits would have been present in the dry season of 1981, all other things being equal. If more stigmas were snipped because more buds were attacked before they flowered, then even fewer fruits would have been fertile. Thus the food situation could have been precarious for those territory owners had 1981 been a drought year, especially for those individuals with smaller territories.

But 1981 was not a drought year. Small seeds provided an abundant alternative to Opuntia fruits and the subsequent cactus flowering was high. Even so, for birds such as 4118 , the number of fertile fruits in their territories could have fallen dangerously low. It may not be a coincidence that this bird was involved in intense territorial disputes on several occasions in 1980 (although this was not quantified).

Territory size presumably decreases as finch density increases. When this is combined with low alternative food availability, as in 1977, the effects may be drastic. In that year, all first-year birds and $55 \%$ of adult $G$. scandens died over the dry season (Boag 1981; Grant and Price 1981).

Clearly the mating advantage and the postulated survival advantage of high territory quality are related. A female, once mated, remains on that territory most of the time, although a small minority change mates (Millington MS). Females do wander occasionally, especially when accompanied by dependent juveniles, but in September 1979 females were rarely seen off territory. A female choosing among males will clearly do better if that male has a territory likely to get them both through adverse conditions, e.g. food shortage.

The relative importance of reproductive and survival advantages vary in time. We suggest the mating advantage is generally more important at low densities when the food to finch ratio is high, such as during the study period, and the survival advantage is generally more important at high densities when the food to finch ratio is low. A comparison of the territory quality of survivors and non-survivors after a drought year is needed to test this.

Thus sampling the population in a year of high rainfall and even sex-ratio could well lead to the conclusions that (1) territory quality is unimportant if reproductive success remains relatively uniform, and (2) the owner may be defending a larger territory than it needs (cf., Verner 1977). This point was made by MacLean and Seastedt (1979) and, like those authors, we emphasize the need for longerterm studies of variations in territory quality in relation to the survival and reproductive success of their owners.

Acknowledgments. This research was supported by N.S.F. grants DEB 77-23377 and DEB 79-21119 to P.R. Grant. We thank T.D. Price for field assistance and R.B. Payne and T.D. Price for comments on the manuscript. The Charles Darwin Research Station provided logistical support.

\section{References}

Abbott I, Abbott LK, Grant PR (1977) Comparative ecology of Galápagos ground finches: evaluation of the importance of floristic diversity and interspecific competition. Ecol Monogr 47:151-184

Boag PT (1981) Morphological Variation in the Darwin's Finches (Geospizinae) of Daphne Major Island, Galápagos. Ph.D. thesis, McGill Univ

Gill FB, Wolf LL (1975) Economics of feeding territoriality in the Golden-winged Sunbird. Ecology 56:333-345

Grant BR, Grant PR (1981) Exploitation of Opuntia cactus by birds on the Galápagos. Oecologia (Berlin) 49:179-187 
Grant PR, Smith JNM, Grant BR, Abbott IJ, Abbott, LK (1975) Finch numbers, owl predation and plant dispersal on Isla Daphne Major, Galápagos. Oecologia (Berlin) 19:239-257

Grant PR, Grant BR (1980) Annual variation in finch numbers, foraging and food suppy on Isla Daphne Major, Galápagos. Oecologia (Berlin) 46:55-62

Grant PR, Grant BR, Smith JNM, Abbott IJ, Abbott LK (1976) Darwin's Finches: population variation and natural selection. Proc Nat Acad Sci USA 73:251-261

Grant PR, Price TD (1981) Population variation in continuously varying traits as an ecological genetics problem. Am Zool $21: 795-811$

Holling CS (1966) The functional response of invertebrate predators to prey density. Mem Entomol Soc Canada No 48, 1-86

Janzen DH (1980) Heterogeneity of potenial food abundance for tropical small land birds. In: Keast A, Morton ES (eds) Migrant Birds in the Neotropics. Smithsonian Institution Press. Washington, D.C.

Karr JR (1976) Seasonality, resource availability, and community diversity in tropical bird communities. Am Nat 110:973-994

MacLean SF Jr, Seastedt TR (1979) Avian territoriality: sufficient resources or interference competition. Am Nat 114:304-307

Millington SJ (1982) The breeding biology of the Cactus Finch Geospiza scandens on Isla Daphne Major, Galápagos. MS
O'Donald P (1977) Sexual selection and the evolution of territoriality in birds. In: Christianson FB, Frenchel TM (eds) Measuring selection in natural populations, Lecture notes in biomathematics no. 19, Springer, Berlin

Price TD (1983) Sexual selection on body size, plumage and territory variables in a population of Darwin's finches. Submitted to Evolution

Schluter D (1982) Seed and patch selection by Galápagos ground finches: relation to foraging efficiency and food supply. Ecology $63: 1106-1120$

Smith JNM, Grant PR, Grant BR, Abbott IJ, Abbott LK (1978) Seasonal variation in feeding habits of Darwin's ground finches. Ecology 59:1137-1150

Stiles FG (1973) Food supply and the annual cycle of the Anna Hummingbird. Univ Calif Berkeley Publ Zool 97:1-109

Verner $J(1977)$ On the adaptive significance of territoriality. Am Nat $111: 769-775$

Wiggins IL, Porter DM (1971) Flora of the Galápagos Islands. Stanford University Press. Stanford, California

Zimmerman JL (1971) The territoriality and its density dependent effect in Spiza americana. Auk $88: 591-612$

Received November 8, 1982 